of infiltration of the submucosa. Some, notably Aschoff, relegate it to the angioblastomas. Its colls are so ordered, fiattened, and clear that this conclusion is tempting. Other histologists, interpreting these cell appearances as results of low grade anaplasia and tissue pressure, regard the growth as carcinomatous, but of such low malignancy as never to occasion metastases, nor, in the words of Boyd, " to cause the death of a patient."

This case shows that under unfarourable conditions, of which the time factor is one, an appendicular neoplasm can at least infiltrate, and has encompassed the dcath of a patient. It is evident that this growth, or its probable predecessor, chronic appendicitis, had been troubling our patient for years, and, unfortunately for her, not very severely. Indeed, but for the fortuitous offices of her overzealous "policeman of the abdomen," the great omentum, she might yet be harbouring a neoplasm of the appendix, still " henign," with little to show for it beyond dyspepsia.

In 90 per cent. of all cases the incidence of the morbid process is at the tip of the appendix. More fortunate, howerer, is the lot of the 10 per cent. in whom it is found (incidentally and accidentally) in the proximal part, for in this region the early narrowing of the lumen leads to appendicitis of the obstructive type, calling for immediats intervention and its removal out of harm's way, as in the series of cases recorded by Wilkie.

It may be argued that our case is in no way comparable with the typical appendicular neoplasm; that, indeed, it bears the stamp of an evident adeno-carcinoma such as may be found anywhere in the alimentary tract. If that is so, it must be unique and all the more interesting. It must be admitted that macrosdopically it is only by straining the imagination that we could describe its colour as yellow. From its histological appearances we should prefer to suggest that it is transitional between the hitherto described "benign carcinoma" of the appendix and the frankly malignant group of alimentary adeno-carcinomas in general. Microscopically, it bears an undoubted resemblance genetically to the so-called "benign carcinoma"; but it has infiltrated, and it certainly exhibits rather more anaplasia in the omentum, where tissue pressure relaxes, and the cell, ever impatient of restraint, automatically becomes more wayward.

\section{ETHER CONVULSIONS.}

\section{BY}

W. STANley SyKes, M.A., M.B., B.Ch., D.P.H., ANAESTHETIST TO THE LEEDS GENERAL INFIRMARY.

Convussions during anaesthesia are rare, but when they occur they are both dramatic and dangerous. The tragically sudden death of one of my own patients aroused in me a desire to know more about this subject, and led me to make the following collection of existing theories. My own case corresponds very closely indeed with those described by Wilson', and may be taken as typical.

The patient was a young adult, aged 28 , with a septic lesion (pyosalpinx). The induction was uneventful, and the anaesthesia proceeded without incident for thirty to forty minutes. Suddenly, withoul previous cyanosis or warning of any kind, twitchings of the face appeared, which spread to the arms and legs until the whole body was in clonic convulsions and the patient had to be held on the table. There was no primary failure of the heart or respiration. Cyanosis did not occur until convulsions had been in progress some time, and was only slight. Death took place before it was well marked. (The death rate is nearly 25 per cent. in the recorded cases. It must be clearly understood that the convulsions come on when the patient is properly under.

Most of the published accounts regard the convulsions as an entirely new phenomenon, the first crop of cases occurring in 19ட5-26. One observer, ${ }^{2}$ however, saw five cases between 1913 and 1925, so that this is not strictly true. Another case is on record dating from 1922. It is certain, however, that they are much more common now than formerly. It may be argued that they occurred before, but passed unnoticed because of their rarity, and it is true that even now they are very rare. 'MrCardie ${ }^{3}$ in thirty-two year's' anaesthetic practice never saw a case at all, and many other anaesthetists of vast experience are in a similar position. I have seen one case in nearly 5,000 administrations. On the other hand, it is the rarities which get described in the journals, and ether convulsions are so umprecedented and so fatal that it is justifiab!e to assume their incidence before 1525 to be infinitesimal, or some of them would surely have been reported. Delared chloroform poisoning is also extrenely rare, and not nearly so evidently connected with anaesthesia as these convulsions sire, but in spite of this it has been known to the textbooks for decardes.

\section{Theories of causution.}

The obscurity of the subject is well illustrated by the number of theories purporting to explain it.

Muskens 4 states: "In my book Epilepsy. I have been able to assemble evidence . . . to prove that the period of transition from unconsciousness to consciousness, as in waking from sleep, is the period par excellence for the occurrence of epileptic phenomena. Further, a latent tendency to epileptic manifestations is frequently betrayed for the first time at this period.... The period of transition from unconsciousness induced by a narcotic $\ldots$ is associated with the same tendency. ... The evidence afforded seems to me to suggest the question : Why are epileptic manifestations so comparatively rarely seen in persons emerging from narcosis?"

This hypothesis aiters the facts to fit the theory. Ether convulsions begin during the surgical stage of anaesthesia, and not during the emergence from narcosis. Their most startling and characteristic feature is the sudden occurrence of movements in a person who ought, by all previous experience, to be absolutely immobile. In every recorded case the convulsions began when the patient was either stated or implied to be under. My own case was sufficiently under for the surgeon to sew up the peritoneum without comment. Muskens is either confusing the condition with true epilepsy (during induction or recovery) or with the harmless ether tremor of light anaesthesia. It bear's no resemblance whatever to this or to the jactitations of gas administration. Incidentally, most reports, including my own, give a negative history of epilepsy.

Fairlie $^{5}$ draws attention to the use of the Pinson bomb in a large percentage of the cases. In 11 of Pinson's $15,{ }^{6}$ and in one recorded by Dickson, ${ }^{7}$ this was the method employed. Fairlie suggests that the bomb is the cause, possibly because of something inherent in its superheating of the elher.

Superheating is peculiar to this method, but since the convulsions may occur in the absence of the bomb the theory breaks down. In my own case an ordinary closed inhaler was used, and in some of the others the open method or Shipway's apparatus.

Fairlie $^{8}$ also suggests that high concentration of ether or excess of $\mathrm{CO}_{2}$ is the cause, both of which, he thinks, are specially liable to occur with the bomb method.

But high concentration of ether and excess of $\mathrm{CO}_{2}$ can also be obtaned by other methods with apparent impunity. In the early years of the century ether was given exclusively in closed inhalers to patients who had received no preliminary medication whaterer (the resulting cyanosis (avsing ether to be disliked hy the suigeons of that generation) and convulsions did not occur. Fxtreme cyanosis is of ten seen during inexpert nitrous oxide administration, but it produces nothing more serious than the jactitations of the textbooks, which cease as soon as air or oxygen is givon. Again, true ether convulsions are not ushered in by cranosis.

Hewer ${ }^{9}$ brings forward the additional argument that convulsions have occurred during endotracheal administration, when the $\mathrm{CO}_{2}$ content of the alveolar air is less than normal. Pinson ${ }^{10}$ blames high concentration of $\mathrm{CO}_{2}$, while denying that the bomb is a factor in its production. The same objections apply as in the preceding paragraph.

Hornabrook ${ }^{11}$ holds that ether is not to blame, but that the atropine given before anaesthesia is the cause, a dose safe enough in itself being an overdose to a patient under ether.

It is true that atropine in poisonous amounts will cause convulsions, but it is difficult to believe that routine doses can have this effect, when it is common knowledge that they are insufficient to produce the other manifestation of atropinism-pupillary dilatation. If they did, convulsions would be very common and the synergism would be well 
known, in the same way that the dangers of chloroform combined with adrenaline are well known. Atropine was in use for rears before convulsions were noted. Sington'? remarks that at Great Ormond Street $1 / 100$ grain is given to all children of 4 and upwards before every operation. Over 7,000 operations take place every year, and no convulsions have occurred. Most of the convulsions recorded are in voung adults and the dose of atropine usually given is not greater than those mentioned above, which have been proved safe for children.

Gwathmey ${ }^{13}$ puts forward an exactly opposite explanation. Referring to Wilson's paper, ${ }^{15}$ he disagrees with the impurity theory and states that Wilson, in his post-mortem report, mentions the cause of death but overlooks it: "the lungs were congested and a small amount of frothy fluid exuded on pressure." Gwathmer found that in animals ether had no effect on the lungs after preliminary medication. In unmedicated controls the lungs were distended, congested, oedematous, and contained petchiae Sometimes atelectasis and oedema of the alveoli and bronchi took place as well. This, he states, might cause the convulsions by diminishing the oxygen supply.

If this be true, ether convulsions should have been of frequent occurrence during the half-century before the introduction of preliminary medication, and should have cleclined to vanishing point as the practice became universal. The reverse is the case. Ther should also occur more frequently in out-patient and general practice, whereas all the reported cases seem to be in in-patients, who rarely escape the prelininary dope.

McDonagh's explanation 14 is original, complex, and comfortably dogmatic. ". . . Anaesthetic substances act by subjecting the prolein particles in the plasma to stdden dehydration, and then to an equally stidden hydration. In the first process the protein particles go into solution, and in the second process they ... tend to become precipitated in ... the brain. It is to the protein particles becoming arrested in the cerebral vessels that the loss of consciousness is due. Should the hydration persist, or increase to a point where the surrounding nerve cells are damaged, then convulsions, conra, and death are liable to occur..... It thus comes to pass that there is no fundamental difference between the convulsions occurring during anaesthesia and the convulsions ... that are met with in ... shock, eclampsia, gtat us epilepticus, tetany, etc."

This is abstruse, and, I think, not free from discrepancies. If anaesthetic convulsions are identical in cause with eclamptic and epileptic fits why should anaesthetics be an infillible method of stopping these fits, as in fart they are? According to this theory anaesthesia should make them worse. Again, the theory does not explain why the hidrated protein particles should only have produced deleterious results during the last few years.

The late S. R. Wilson ${ }^{15}$ attributed the convulsions to impurities in the ether, which must for historical reasons have recently arisen, due either to changes in the method or materials of manufacture or to modern methods of administration. His paper should be read by all interested in the subject. He concluded that the cases did not correspond to any known form of anaesthetic collapse, and that the safety of ether was seriously assailed. All the patients were young and most of them toxic He recommended that only pure ether be used, and that it should be periodically tested and always stored away from ligh and air. Amber bottles and bone or ivory tubes shourd be used for Shipway's apparatus and stale ether discarded. All convulsions should be reported and the ether preserved.

The above precautions were all proved to be desirable by Wilson's experiments on the formation of peroxides and aldehvdes in ether, but $\mathrm{my}$ own case, among others, demonstrates that impurities are not the sole cause. Aether puriss. (B.D.H.) was used from a stock bottle of amber glass wrapped in black paper, so that the action of light can be excluded. A clean closed inhaler was used, so there was no question of stale ether or the production of impurities by gaseous bubbling. The makers sent me an analysis of the batch of ether as marketed, which showed it to be pure, but, as many people had access to the anaesthetic room, it was quite possible that stale ether trad been poured back into the bottle. The makers kindly analysed samples from this, and the results showed that no deterioration had taken place except for slight traces of mechanical dirt. Peroxide was less than $0.05 \mathrm{per}$ million and aldehydes were absent. Wilson claims that these are toxic if present to the extent of 0.5 per cent.
Overdosage is suggested by Kirkby Thomas. ${ }^{16}$ My own case was never very deeply anaesthetized. The patient was an easy subject and sufficiently relaxed when moderately under. I have had hundreds of patients far more deeply under without incident.

Hadfield ${ }^{17}$ suggests some unrecognized impurity, but himself dismisses this theory because the stspected batches of ether have been used for many other patients without ill effects. The same writer 18 quotes an explanation from an unnamed source to account for the sudden ontbreak in 1926. At the end of the war the Government sold large stocks of good ether, and manufacturers used them instead of making their own. As soon as these stocks were exhausted and ether manufacture was restarted convulsions began to be noticed.

Hadfield's inquiries as to the truth of this story were met with denials, as were $\mathrm{my}$ own. In any case the story collapses on examination. The Government ether was not a gift from the gods. Presumably it would come from the same sources as civilian cther, sources which would be working continuously before, during, and after the war. The army consumption was so enormous that the Government was very unlikely to accumulate sufficient stocks to last the whole country, including the Ministry of Pensions, for eight years. Hien if this happened, as Hadfield pertinently remarks, " are we to beliere that on resuming manufacture they all became so inefficient as to produce ether which caused symptoms never produced by even the worst ether during the previous seventy vears?" Finally, in many cases, including my own, the ether was found to be pure.

Hadfield19 suggests idiosyncrasy with a qualification. "Probably in all cases it is necessary for one or more of sereral other conditions to be present at the same time." Heat, sepsis, or other toxaemia, impurities in the ether, and youth in the patient, are the other factors assumed to be necessary in addition to personal idiosyncrasy. He illustrates this by a case described as "some thyroid condition." Two operations took place, both attended by convulsions, the second time fatal. Here thyroid toxaemia was present on both occasions. One of Wilson's cases also fits this hypothesis. A patient had an anaesthetic for an open fracture with no ill effects. Three days later another for gas gangrene was accompanied by fatal convulsions. Here the accessorx factor only came into play on the second occasion.

But, on the other hand, one of McDonald's cases, ${ }^{20}$ a girl of 2, had slight non-fatal convulsions during an operation for cicatricial contracture of the fingers following burns. Two anaesthetic's were given to her afterwards without any trouble, a fact which is inexplicable on the hrpothesis of idiosvncrass. It is interesting to note that this is one of the few non-septic cases on record, thus forming a double argument against the theory.

A case described by Bull21 here crops up awkwardly. In 1919 (again an early date) he met with convulsions in an Arab woman at Basrah. The climate was too hot for ether, and chloroform was used.

This is a strong argument against all the theories which accuse the ether itself. In this case no oxigen was used (see below).

Mennell22 suggests over-oxygenation. The eight cases which had come to his knowledge were all flooded with oxygen and deeply anaesthetized.

This may be considered in sereral different ways:

(a) Over-oxygenation pure and simple. As an example of the untoward effects of a normal and essential gas there is a condition known to deep-sea divers as oxygen intoxication, but here the gases are supplied under great pressure and the conditions are different. It is for the physiologists to find out whether convulsions can be produced by a mere excess of oxygen at normal pressure. it seems unlikely, because they form a feature of the second stage of asphyxia. My own case was supplied freely with oxygen.

(b) The production of impurities in the ether by the action of oxygen. The comparative unimportance of these has already been dealt with.

(c) The ability of the nerve cells to absorb more ether in the presence of oxygen. It is true that oxygen often helps to deepen the anaesthesia in a difficult case, but this effect is automatically limited by its sedative action on the respiratory centre. Also, as in my own case, the convulsions may occur when the patient is not excessively deeply anaesthetized.

(d) There is another possibility which bas apparently been overlooked-impurities in the oxygen itself. In favour of this 
is the fact that oxygen is far more generally used now than it used to be. Formerly a cylinder stood in a remote corner, and was only resorted to, somewhat shamefacedly, when the patient was either blue or moribund. Now it stands at the anaesthetist's elbow and is in constant use, either in a gas and oxygen machine or as the motive power for a Shipway or in comncxion with an ordinary closed or open method. This appears to fit in historically, but it is purely speculative. It is put forward because all the other theories appear to be faulty on examination.

\section{Conclusion.}

In view of the lack of real knowladge it would be an excellent plan if all cases, fatal or not, were notifiable and underwent a full investigation on the lines suggested by the above theorics. The condition is so rare that individuals camnot solve the problem. I regret that the oxygen used in my own case was not examined, but the possibility of this being at fault only occurred to me after collecting, examining, and rejecting the published explanations. It would be worth while investigating this point in any future cases.

REFERENCES.

IS. R. Wilson : Lancet, May 28th. 1927, p. 1117. 2 Kirkby Thomas, Proc Royy. Soc. Medl., vol. xxi, No. 10, p. 1705. 3 ibid., p. 1706. 4 British Medical

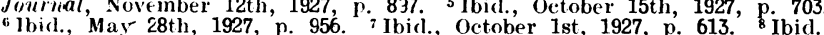

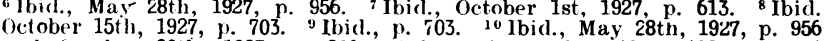
and October 29th. 1927, p. 806." HI Ibid., September 10th, 1927, p. 471. 12 Jbid., September 24th, 1927, p. 565. 19. Lancet, June 25th, 1927, p. 1369 14 Britixh Medical Journal, Dectmber 10th, 1927, p. 1119. 15 Lancet,
Mav 28th, 1927, p. 1117. 10 Proc. Roy. Soc. Mell., vol. xxi, No.10, August,

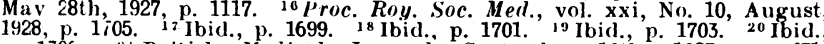
p. 170. ${ }^{21}$ British , Medical Journai, 'September 10th, 1027, p. 471. 22 P'roc. Roy. Soc. Med., vol. xxi, No. 10, p. 10-5.

\section{SPONTANEOUS HAEMATOMA OF THE RECTUS ABDOMINIS MUSCLE.}

\section{With a Repont of Two Cases.}

BY

PERCY MALPAS, Ch.M., F.R.C.S., HONORARY ASSISTANT GYNAECOLOGICAL SURGEON, BOGTLE GENERAL HOSPITAL; DEMONSTRATOR OF ANATOMY IN THE UNIVERSITY OF LIVERPOOL.

RECORDED cases of spontaneous haematoma of the rectus abdominis muscle are not very numerous, although it would appear from reports of discussions on the subject that the condition is seen more frequently in clinical practice than is generally supposed. It has seemed worth while to record the present two cases, which occurred in close succession in hospital, as they appear to throw a little light on the etiology and diagnosis of the lesion.

In England Fothergill ${ }^{4}$ and Andrews ${ }^{1}$ have described similar cases, but the most extensive series of cases are those collected by Wohlgemuth, Perman; ${ }^{7}$ and Culbertson. ${ }^{3}$ These three writer's have reviewed all the varieties of haematoma occurring within the rectus sheath, not confining themselves to the spontaneous group. In a more recent paper Halperin ${ }^{6}$ further discusses this last group, and describes another instance of the condition.

It is generally agreed that haematomas of the rectus muscle may be divided into three groups. In the first group are such haematomas as occur during violent effort, usually in athletes, where the haemorrhage is secondary to a partial or complete rupture of the muscle. In the secoird group may be placed the haematomas met with in the course of infections, such as typhoid fever or influenza; they were a feature, according to Cole, ${ }^{2}$ of the influenza epidemic of 1917. In such cases there is manifestly a local lesion of the muscle pieceding the hacmatoma. To this group also belong those well-defined cases which occur in pregnancy, labour, or the puerperium. The third group of haematomas, of apparently spontaneous origin, and of which the present two cases are examples, has special points of interest. The etiology is obscure, and the clinical picture gains importance from its similarity to that of an " acute abdomen.".

CASE I.

A man, aged 63, was admitted to hospital with a provisional diagnosis of some form of intestinal obstruction. He gave a history of having suffered from chronic bronchitis for many years; he had, in addition, been troubled with excessive bleeding after minor cuts and teeth extractions since childhood. He had, indeed, been regarded by his relatives as a "bleeder." During a fit of coughing he experienced a sharp intense pain in the left lower abdomen. The pain remained severe for a few hours, during which time he vomited repeatedly; it then subsided to a persistent dull ache. He was sent to hospital on the third day of the illness.

An ill-defined, non-tender swelling was found in the abdominal wall, corresponding in position to the left rectus sheath; it extended upwards to the umbilicus, and downwards to the pubis. The overlying skin was normal, but there was a definite ecchymosis present over the left half of the scrotum. Apart from some evidence of chronic bronchitis no other abnormal physical signs were found. The blood count was normal; the platelets were not counted; the bleeding time was normal. He was kept under observation in bed, but on the eighth day of the illness the pain recurred, the haematoma increased in size, and exploration was decided upon.

At the operation the subcutaneous tissues were found to be normal. The rectus muscle itself was infiltrated with dark brown blood clot, but no rupture of the muscle was to be seen, and there was no free blood in the peritoneal cavity. Removal of the clot was impossible owing to its intimate connexion with the fibres of the rectus muscle itself. There was a very free oozing of blood from the muscle during the operation, and haemostatic mattress sutures were'necessary. After the operation a slight-but steady oozing of blood from the wound persisted for two days; it was treated with local pressure and the subcutancous injection of $10 \mathrm{cccm}$. of normal horse serum. The temperatire ranged from $98^{\circ}$ to $99.5^{\circ} \mathrm{F}$. On the fourth day after operation he suddenly collapsed, vomited about two pints of dark blood, and died within the hour. No necropsy could be performed.

\section{CASE II.}

A woman, aged 43, was sent to hospital suspected of having a twisted ovarian cyst. She stated that during a severe fit of coughing she felt a sharp pain in the right lower. abdomen; this pain made her feel very giddy, and she vomited twice during the next hour. After two hours the pain somewhat abated, but any active movement elicited it afresh. During the previous few years she had noticed that the slightest injury would cause bruise; she had also been subject recently to attacks of bronchitis; otherwise she had always been a healthy woman, and her menstrual history was normal. She had had two normal labours.

On examination I found a tender swelling of the lower half of the right rectus muscle. The skin overlying the swelling was normal, but on the right labium majus there was a recent, though faint, ecchymosis. In addition several bruises, both recent and fading, were present on the legs and arms, although she recollected no injury. Blood examination revealed no abnormality, but a platelet count could not be made.

She was kept under observation for two weeks, by which time the swelling had almost disappearcd. As the pain and tenderness had by that time quite disappeared, she was discharged from hospital.

A comparison of the foregoing cases with those previously described in the literature enables a criticism to be made of the etiological factors concerned in the production of these spontaneous haematomas-abdominal apoplexies, as they have been called. The very rarity of the lesion points to some other cause than the concurrence of the strain of coughing, which is the usual exciting cause, and the special anatomical features of tho deep epigastric artery. Moreover, the operative findings show that the primary lesion is neither a rupture of the muscle nor of the artery.

It appears most probable that these spontaneous haematomas are related to systemic affections. In the present two cases the underlying cause was the coexistent blood disorder, manifested in the one instance by the history and the terminal haematemesis, in the other by the history and the simultaneous presence of subcutaneous haemorrhages in other parts of the body. This relationship of spontaneous haematoma of the rectus muscle to a haemorrhagic diathesis has not been previously emphasized, but Stoeckel $^{8}$ has described a similar case associated with generalized petechiae. Moreover, Lockyer, in a discussion of Andrews's cases, called attention to the frequency of such haematomas in pregnancy complicated by renal changes, and either abortion or accidental haemorrhage. In this regard it is now recognized generally that a fairly large proportion of the accidental haemorrhages of pregnancyin some ways a not dissimilar condition-are related to systemic affections, though not indeed to blood disorders with any frequency.

The immediate cause of the haemorrhage into the rectus in these cases is probably, as Grignani ${ }^{5}$ states, the prolonged capillary and venous congestion produced within 